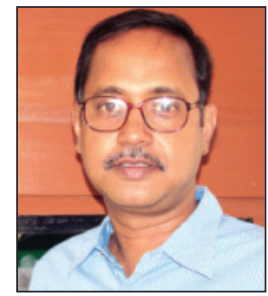

JOURNAL OF MINES, METALS \& FUELS www.jmmf.info

\title{
Owning up mining industry megatrends: steps taken by a public sector company
}

Luossavaara Kiirunavaara Aktiebolag (LKAB) is owned by the Swedish government. LKAB is an international high-tech minerals group that mines and upgrades the unique iron ore of northern Sweden for the global steel market. Sustainability is the core to its business and its ambition is to be one of the industry's most innovative, resource-efficient and responsible companies. The group had sales of more than SEK 16 billion in 2015 and employs about 4,500 people in 14 countries. Other group business includes industrial minerals, drilling systems, rail transport, rockwork services and property management.

LKAB's strategy paves the way for zero carbon dioxide emissions from its own processes and products by the year 2045 and secures the company's operations beyond the year 2060. The strategy will mean a historic transformation through comprehensive changes of the company's operations and a new position on the market. LKAB has embraced upon the biggest transformation in the company's 130-year history, which could become the biggest industry investment ever in Sweden. Our strategy creates unique possibilities for us and Swedish industry to take the lead in a necessary conversion.

Their strategy consists of changes in three major areas:

1. New world standard for mining. Through digitalisation, automation, electrification, new operation methods and carbon dioxide-free production to set a new world standard for mining.

2. Carbon dioxide-free sponge iron with hydrogen technology. Through the shift from iron ore pellets to carbon dioxidefree sponge iron we will take an important step forward in the value chain, increase the value of the products while giving our customers direct access to carbon dioxide-free iron for steel production.

3. Extract critical minerals from mine waste. Using fossil-free technology we will extract strategically important minerals and phosphorus for mineral fertilizers from today's mine waste.

It considers these goals for sustainable growth:

i. Social goals

a. Reduce accidents leading to absence from work to a frequency of 3.5 per million work hours by 2021 (2015: 6.9) b. The proportion of women/female managers in the company shall reach at least 25 per cent by 2021 (2015: 20 per cent $/ 18$ per cent)

c. Compliance with LKAB's Code of Conduct and having a well-functioning dialogue with stakeholders.

ii. Financial goals

a. Return on equity shall exceed 12 per cent over an economic cycle

b. Net debt/equity ratio 0-30 per cent

c. Ordinary dividend shall amount to $40-60$ per cent of the year's profit

iii. Environmental goals

a. Reduce emissions of dust into the air from treatment facilities by 40 per cent by 2021 compared to 2015 , calculated as an average for all the facilities

b. Reduce emissions of nitrogen into water by 20 per cent per tonne of finished product by 2021, compared to 2015

c. Reduce carbon dioxide emissions by 12 per cent per tonne of finished product by 2021 compared to 2015 , and at the same time reduce emissions of nitrogen into the air

d. Reduce the energy intensity (kilowatt hours per tonne of finished product) by 17 per cent by 2021, compared to 2015

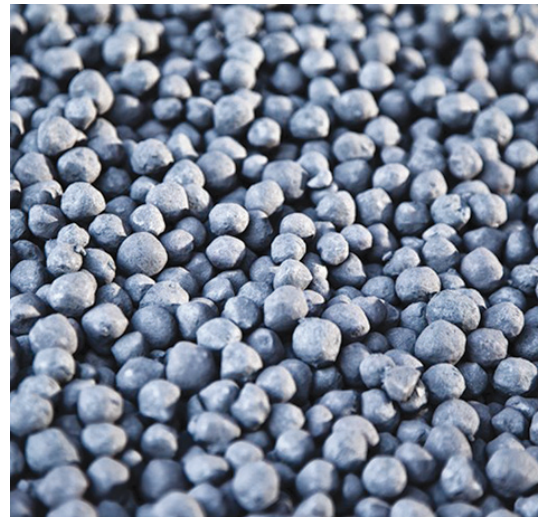

LKAB's iron ore pellets are made from magnetite and have high iron content, around 67 per cent
These two factors give impact both during the pelletizing process and during steelmaking, than competing pellets and sintered hematite fines. The high iron content in the ore in combination with thoroughly tested and balanced additives allows increased steelworks productivity. At the same time, it lowers energy requirements and lower slag volumes a lower environmental 